\title{
Acute monoblastic leukemia
}

INSERM

\section{Source}

INSERM. (1999). Orphanet: an online rare disease and orphan drug data base. Acute monoblastic leukemia. ORPHA:514

Acute monoblastic leukemia (AML-M5), is one of the most common subtypes of acute myeloid leukemia (AML; see this term) that is either comprised of more than $80 \%$ of monoblasts (AML-M5a) or 30-80\% monoblasts with (pro)monocytic differentiation (AMLM5b). AML-M5 presents with asthenia, pallor, fever, and dizziness. Specific features of AML-M5 include hyperleukocytosis, propensity for extramedullary infiltrates, coagulation abnormalities including disseminated intravascular coagulation and neurological disorders. Leukemia cutis and ging ival infiltration can also be seen. A characteristic translocation observed in AML-M5 is t(9;11). 